\title{
Empirical Study of Quantitative Investing Model
}

\author{
Xinyue Liu
}

Indiana University Bloomington, Franklin Hall 306, 601 East Kirkwood Avenue, Bloomington, IN

47405-1223, USA

xinyue009@163.com

Keywords: Quantitative Investing; CSI 300 Index; Stock Market of China.

\begin{abstract}
After developing for over thirty years, quantitative investing has become a mainstream investment strategy with a global gaze. However, for ordinary people, the principle of quantitative investing model and the reasons for its profitability is seldom known. In this paper, I elaborate the basic principles of three classical models on ATR Channel Breakout, Bollinger Breakout and RSI Trend Catcher, to separately carry out empirical study regarding the historical data of the CSI 300 index.
\end{abstract}

\section{Characteristics and Advantages of Quantitative Investing}

Quantitative investing refers to an investing technology, involving highly professional skills in programming, mathematical modeling, or statistic analysis, to reach comparatively sophisticated and condensed decisions on managing capitals of funds. Different from conventional methods concerning investing, the quantitative investing relies on appropriate intentions, quantitative investing rely on appropriate investment ideas, investment experience included in quantitative investing model, and use computer to process a large amount of information and establish reusable and optimizable investment strategy, to guide our investment decisions. Unlike conventional investing strategies, quantitative investing is based on huge amount of debase, instead of personal experience, and its resulting framework could be easily understood by people without any mathematical background. All mentioned are contributed to the predominating and overwhelming application to various funds. Characteristics and advantages of quantitative investing include the following:

Firstly, quantitative investing is not opposite to fundamental analysis. It is also not technical analysis, but logical investment philosophy and investment approach based on an overwhelming understanding of the market.

Secondly, quantitative investing is an active investment and totally different from index investment. Its principle is that the market is so invalid, or weak valid that investors are able to take the initiative to build an excess returns combination to beat the market.

Thirdly, the essential intention of quantitative investing strategy is for a more lucrative opportunity of investment. In order to reach returns as maximum as possible, quantitative investing model needs to be focused on the estimation and discrimination of future returns on assets.

Finally, quantitative investing model is just a tool, and the probability of whether it would success actually depends on the understanding degree of investors on quantitative investing. Meanwhile, quantitative investing models contain the process of continuous tracking, optimization, and demonstration.

\section{Construction of quantitative investing Models}

ATR Channel Breakout Model. ATR Channel Breakout model is a kind of volatility channel breakout system which utilizes the average channel index as the price fluctuation index. Under this mode, investor enter the market depends on the timing when the closing price is higher than the upper channel of ATR; when the closing price of the day before is lower than the lower channel of ATR, quit the market. For the market which can be shorted, the case is just opposite: when the 
closing price is lower than the lower channel of ATR, short the stocks in the second trading day; when the closing price returns to the ATR channel, quite the market.

China's stock market does not allow short, and therefore the market of China is equivalent to a separated one where we only consider running long in model construction. Under our ATR model, we regard average closing price of 80 days plus thrice 39 days ATR as its upper channel, and average closing price of 80 days plus 39 days as its quit line.

Bollinger Breakout Model. Bollinger Breakout model was proposed by Chuck Lebeau and David Lucas in 1992. Its principle is roughly the same as ATR Channel Breakout model, apart from measurement of price fluctuations. Under Bollinger Breakout model, we adopt a standard deviation of 80 days' closing price instead of ATR. Similarly, when the closing price is higher than that of the upper channel of Bollinger, investors will enter the market in second trading day; when the closing price returns to that of the ATR channel, investors will quite the market. Under our model, the upper channel is the average closing price of 80 days plus twice standard deviation, and the lower channel average closing price of 80 days plus one standard deviation.

RSI Trend Catcher Model. RSI Trend Catcher model is different from both of the above models, which are to generate trading signals by relative strength index (RSI). Its principle is based on the calculating method of obtaining digital balance of power between buyers and sellers. For example, there are 100 people about to buy or sell a brand of a commodity, more than 50 of whom want to buy the product and then compete bidding. Then the commodity price will rise. Conversely, if more than 50 people are scrambling to sell, the commodity prices will naturally fell.

RSI is to calculate relative strength index between buyers and sellers over a past period of time. Its calculation method is as follows:

$$
\begin{gathered}
R S=\frac{\text { Average of closin } g \text { price risin } g \text { days }}{\text { Average of closin } g \text { price falling days }} \\
R S I=100 \times \frac{R S}{1+R S}
\end{gathered}
$$

With the help of the formula above, we can see that all the volatility in the stock market is between 0 and 100 . According to normal distribution, RSI values are mostly changing in the range of 30-70. If the value is no less than 50 , we believe there is a competitive buyer power; if it is less than 50, we believe there is a stronger seller power, and the price will fell definitely. Generally, when it reaches 80 or 90 , the related market will be overbought. Therefore, at this point, market price will naturally fall and be adjusted; when the price falls below 30, it is considered to be oversold. As a result, a market rebound will occur.

In RSI Trend Catcher model, we set the limits for trading signals to guide the operation. Generally speaking, defining a range, when the index is greater than a certain value, it is a buy signal; when the index is less than another value, it is a sell signal. The values are often determined based on experience and historical data.

In this model, we set the parameters as Table 1:

Table 1. Parameter setting

\begin{tabular}{|c|c|c|}
\hline Parameter & Description & Value \\
\hline Upper bound & Maximum increase of price & 56 \\
\hline Lower bound & Maximum decline of price & 51 \\
\hline RSI Length & $\begin{array}{c}\text { Number of trading days used in calculation } \\
\text { of RSI }\end{array}$ & 130 days \\
\hline
\end{tabular}

\section{Empirical Analysis}

Research Scope. In this case, we make the empirical analysis of investment of Shanghai and Shenzhen 300 index constituent stocks from September 1, 2005 to February 28, 2013. We respectively ATR Channel Breakout model, Bollinger Breakout model and RSI Trend Catcher model to analyze the relevant historical data within the research scope. Besides investment 
effectiveness is measured through benefits and risks examination and a comparison is made with performance of CSI 300 indexes.

Benefits and Risks Assessment. The quality of the investment model can be measured from two aspects of benefit and risk. Here we adopt some indicators measuring the benefits and risks relation as follow:

Compound Annual Growth Rate (GAGR). Compound annual growth rate refers to annual growth rate of one investment during a specific period. CSI 300 Index closing price in September 1, 2005 is 944.56, and closing price in February 28, 2013 is 2668.84; it experienced 7.5 years, so the compound annual growth in this period is:

$$
G A G R=\sqrt[n]{\frac{E P S_{\text {now }}}{E P S_{\text {base }}}}-1=\sqrt[7.5]{\frac{2668.84}{944.56}}-1=14.9 \%
$$

Longest Drawdown (LD). Longest drawdown is an important measure of risk, which refers to the Maximum value of return rate at the lowest point of product net. The longest drawdown during 2005 to 2013 is:

$$
L D=\max \frac{D_{i}-D_{j}}{D_{i}}=\frac{5877.2-1654.67}{5877.2} \times 100 \%=71.8 \%
$$

MAR Ratio. MAR ratio is the ratio of benefits and risks. Benefits refer to annual growth rate (GAGR), while risks refer to longest drawdown (LD), so the MAR ratio in this period is:

$$
\text { Mar }=\frac{G A G R}{L D}=\frac{14.9 \%}{71.8 \%}=0.21
$$

Modified Sharpe Ratio. Modified Sharpe ratio is a classical method of measuring the relation between benefit and risk. Excess benefit divided by standard deviation, the result is the excess benefit of each specific risk, so the higher the ratio, the better the model. Calculation of Modified Sharpe ratio is as follow:

$$
\begin{gathered}
\sigma=\sqrt{\frac{n \sum_{i}\left(x_{i}-\bar{x}\right)^{2}}{n-1}}=0.353 \\
\text { ModifiedSharpe }=\frac{G A G R-R_{f}}{\sigma}=\frac{14.9 \%-5 \%}{0.353}=0.28
\end{gathered}
$$

Where $x_{i}$ is monthly rate of return; $\bar{x}$ is average monthly income; $\mathrm{n}$ is number of months trading; $R_{f}$ is risk-free rate, here we set it at 5\%.

Annual Sharpe Ratio. This version of the Sharpe ratio is to divide annual rate of return by standard deviation of annual yield. Calculation of Annual Sharpe ratio is as follow:

$$
\begin{gathered}
\sigma^{\prime}=\sqrt{\frac{m \sum_{i}\left(y_{i}-\bar{y}\right)^{2}}{m-1}}=0.814 \\
\text { AnnualSharpe }=\frac{G A G R}{\sigma^{\prime}}=\frac{14.9 \%}{0.814}=0.18
\end{gathered}
$$

Where $y_{i}$ is annual rate of return; $\bar{y}$ is average annual income; $\mathrm{m}$ is number of year trading.

Research Results and Analysis. We use Trading Blox to carry out analog investment in Shanghai and Shenzhen 300 index stocks, respectively by ATR Channel Breakout, Bollinger Breakout and RSI Trend Catcher model. The daily changes in capital of these three accounts are shown in Fig. 1: 


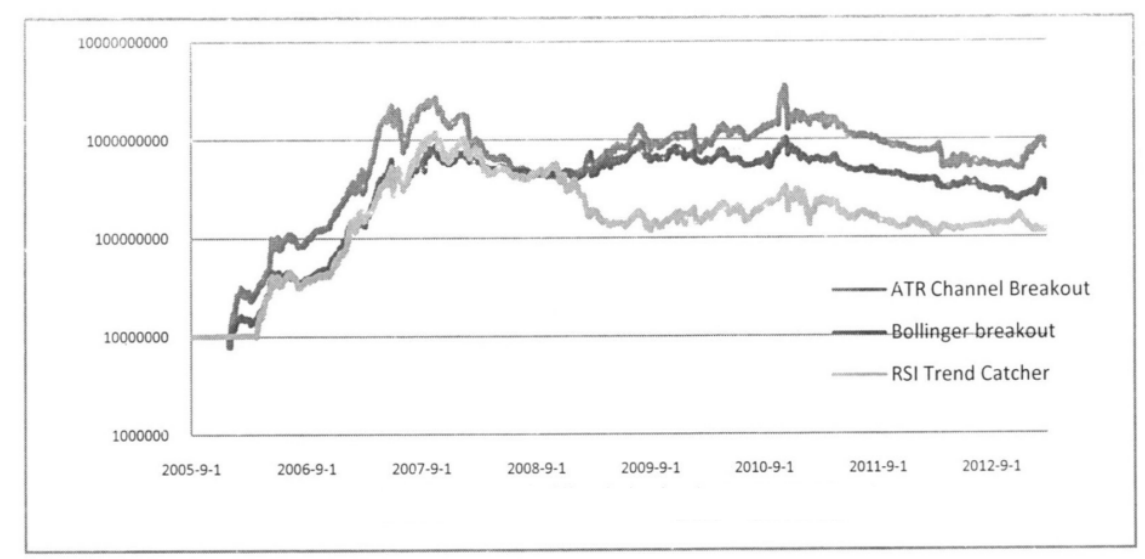

Fig. 1. Fund variation statement

In order to measure the benefits and risks of the 3 models more clearly and accurately, we use the parameters above to analyze the investment results, and compare it with the CSI 300 index, as shown in Table 1:

Table 2. Benefits and risks of the three models and CSI 300 index

\begin{tabular}{|c|c|c|c|c|c|c|c|}
\hline Model & $\begin{array}{c}\text { Ending } \\
\text { Balance }\end{array}$ & GAGR & MAR & $\begin{array}{c}\text { Modifie } \\
\text { d Sharpe }\end{array}$ & $\begin{array}{c}\text { Annual } \\
\text { Sharpe }\end{array}$ & $\begin{array}{c}\text { Max total equity } \\
\text { DD }\end{array}$ & Trades \\
\hline $\begin{array}{c}\text { CSI 300 } \\
\text { index }\end{array}$ & $14.9 \%$ & 0.21 & 0.28 & 0.18 & $71.8 \%$ & 1261 \\
\hline $\begin{array}{c}\text { ATR } \\
\text { Channel } \\
\text { Breakout }\end{array}$ & 889667754 & $81.98 \%$ & 0.95 & 0.88 & 0.08 & $85.9 \%$ & 1154 \\
\hline $\begin{array}{c}\text { Bollinger } \\
\text { Breakout }\end{array}$ & 345929956 & $60.44 \%$ & 0.79 & 0.96 & 0.17 & $76.6 \%$ & 605 \\
\hline $\begin{array}{c}\text { RSI Trend } \\
\text { Catcher }\end{array}$ & 118224796 & $39.03 \%$ & 0.43 & 0.76 & 0.09 & $90.7 \%$ & 0.96 \\
\hline
\end{tabular}

Table 2 shows yield rate of the three models are far higher than the growth rate of CSI 300 index, but their risks are also higher than CSI 300 index. Combining the benefits and risks, we can easily know that MAR ratio and Modified Sharpe of the three models are all higher than CSI 300 index, which the corresponding benefits of per unit risk of model are high.

Thus, as a whole, from the perspective of relative benefits and risks of the three investment model outperform the CSI 300 index, which proves the adaptability of the quantitative investing model for China’s stock market.

\section{References}

[1] Markovitz H. Portfplio Selection: Efficient Diversification of Investment. New York: John Wiley \& Sons, 1959.

[2] Q. Li, Q. Li. quantitative investing APPLICATION IN CHINESE STOCK MARKET. https://www.lap-publishing.com/, 2011.

[3] Y. Ke, S.Y. Zheng. A Research on Quantitative Stock-selection: the Combination of Value Investment and Sector Rotation Investment Strategy. Journal of Fujian Institute of Financial Administrators, 2014.

[4] Andrikopoulos P, Clunie J, Siganos A. Short-selling constraints and 'quantitative' investment strategies. European Journal of Finance, 2013, 19(1):19-35.

[5] Fishwick E. quantitative investing Risk Analysis// quantitative investing Risk Analysis. Butterworth Heinemann, 2014. 
[6] X. Fan, H. Li, Z. Zhu. A quantitative investing model based on multi-fractal theory and support vector machine// Computing, Management and Telecommunications (ComManTel), 2014 International Conference on. IEEE, 2014:239-244.

[7] R. Bao, L.I. Cong. Probabilistic-model-based Quantitative Decision-making on Stock Investment. Journal of Shanghai Maritime University, 2003. 